\title{
EPIDEMIAS EN SERIES MÉDICAS: ENFERMEDADES, PROFESIONALES SANITARIOS Y DILEMAS BIOÉTICOS
}

\section{Epidemics in Medical Dramas: Diseases, Health Professionals and Bioethical Dilemmas}

\author{
Irene CAMBRA-BADII'; Josep-E BAÑOS ${ }^{b}$ \\ ${ }^{a}$ Càtedra de Bioètica. Universitat de Vic - Universitat Central de Catalunya. Vic (España). ${ }^{b}$ Facultat de Medicina, \\ Universitat de Vic - Universitat Central de Catalunya. Vic (España). \\ Correo electrónico: irene.cambra@uvic.cat
}

Fecha de recepción: 31 de agosto de 2020

Fecha de aceptación: 2 septiembre de 2020

Fecha de publicación: 29 de enero de 2021

\section{Resumen}

El año 2020 será recordado, probablemente, como "el año del coronavirus". La pandemia SARS-CoV-2 que azota desde diciembre de 2019 a todo el mundo marcará un antes y un después en la vida cotidiana de muchas personas. Para evitar la propagación del virus, se han impuesto restricciones rigurosas de circulación, cuarentenas y confinamientos como nunca había sucedido. Frente a esta realidad inédita y disruptiva, acudimos a una fuente privilegiada para analizar y aprender sobre las epidemias: el cine y las series. En particular, las series médicas permiten que los espectadores se adentren en el mundo hospitalario y conozcan distintas representaciones de los profesionales de la salud. En este artículo presentamos la descripción y el análisis de seis episodios de series médicas donde se retrata una epidemia como tema central: Urgencias, Anatomía de Grey, Doctor House, The Good Doctor, New Amsterdam y The Resident. La representación de la enfermedad y la epidemia suele ser misteriosa y peligrosa y se representa a los profesionales como héroes dispuestos a sacrificar su propia salud en pos de sus pacientes. Los temas bioéticos se relacionan con el consentimiento informado y la influencia de temas personales de los profesionales en el tratamiento de sus pacientes.

Palabras clave: series médicas; epidemia; representaciones profesionales; bioética. 


\begin{abstract}
Probably, the year 2020 will be remembered as "the year of coronavirus". SARS-CoV-2 global epidemic has hitting countries around the world since December 2019 marking a before and an after in the daily lives of many people. To prevent the spread of the virus, restrictions, quarantines and lockdowns have been imposed like never before. Faced with this unprecedented and disruptive reality, we come up to a privileged source to analyze and learn about the epidemic: cinema and TV series. In particular, medical dramas allow viewers to enter into the hospital world and meet different representations of health professionals. In this paper we present the description and analysis of six episodes of medical dramas where an epidemic is portrayed as the central theme: ER, Grey's Anatomy, House MD, The Good Doctor, New Amsterdam and The Resident. The representation of the disease and the epidemic is often mysterious and dangerous, and professionals are portrayed as heroes willing to sacrifice their own health for the sake of their patients. Bioethical issues are related to informed consent and the influence of personal issues of professionals in the patients' treatment.
\end{abstract}

Keywords: medical dramas; epidemic; professional representations; bioethics.

LAS SERIES MÉDICAS Y LAS REPRESENTACIONES PROFESIONALES

En los últimos veinticinco años han llegado a un público masivo decenas de series que despliegan escenarios de la práctica cotidiana de los profesionales de la salud ${ }^{1,2}$. Su éxito comercial es notable, sobre todo a partir de las plataformas en línea como Netflix y HBO. Dentro de este universo, las series médicas son un género altamente apreciado por la crítica y el público, y permiten que los espectadores se adentren en el complejo mundo hospitalario.

Estados Unidos es uno de los principales productores y distribuidores de series, por lo que la mayoría de las series médicas provienen de este país. De hecho, las primeras aparecen en la televisión norteamericana de las décadas de 1950 y 1960. En ellas el protagonista es un médico en papel de héroe. Ben Casey (TV) (1961-1966) de James E. Moser, Dr. Kildare (TV) (1961-1966) y Marcus Welby (1969-1976) de David Victor son algunos de los nombres de las series y de los propios profesionales, representados como bondadosos, pacíficos, inteligentes, competentes, empáticos y exitosos ${ }^{3-8}$.
Esta representación de los médicos-héroes va cambiando a lo largo de los años. A mediados de la década de 1990 se produce un viraje con Urgencias / ER (TV) (NBC, 1994-2009) de Michael Crichton y Chicago Hope (TV) (Fox, 19942000) de David E. Kelley. A pesar de mantener la imagen positiva de los profesionales, las series de televisión empiezan a poner más énfasis en sus características negativas y en los puntos débiles de sus relaciones interpersonales. Comienzan a presentarse como personajes arrogantes, codiciosos y adúlteros y a exponerse sus errores diagnósticos y terapéuticos. Estos errores se atribuyen a menudo a los propios pacientes, a la burocracia institucional o al proceso de aprendizaje de los residentes, y no al sistema sanitario ${ }^{9,10}$.

En el contexto de aumento de la demanda de atención sanitaria, de la expansión de las habilidades de los médicos y de avances farmacéuticos y tecnológicos, los dilemas éticos empiezan a formar parte de los escenarios ${ }^{1,7,11}$. Las quince temporadas de Urgencias y las seis de Chicago Hope muestran cómo empiezan a exponerse los dilemas éticos y los conflictos asociados al profesionalismo médico. 
En la década del 2000 se produce un nuevo cambio en la representación de los profesionales de la salud y comienzan a surgir los antihéroes. Los primeros son en clave de humor: Scrubs (TV) (ABC, 2001-2010) de Bill Lawrence y el clásico Doctor House / House MD (TV) (Fox, 2004-2012) de David Shore, cuyo cinismo se hizo mundialmente conocido ${ }^{12}$. Tanto Doctor House como Nip/ Tuck, a golpe de bisturí / Nip/Tuck (TV) (FX, 20032010) de Ryan Murphy exponen dilemas éticos y retratan abiertamente sus errores en la conducta profesional y sus comportamientos cuestionables en la relación médico-paciente, en el primer caso en el departamento de diagnóstico y en el segundo en el mundo de las cirugías estéticas. Un análisis de las ocho temporadas de Doctor House ${ }^{13}$ indica que los conflictos bioéticos aparecen asociados mayormente con la privacidad y la confidencialidad, la autonomía y el consentimiento. Sus episodios son útiles para enseñar bioética, aun cuando el protagonista rompe las reglas ${ }^{14,15}$.

Por su parte, Nurse Jackie (2009-2015) renueva el modo de representar a los profesionales de enfermería, colocando como protagonista a una enfermera adicta a las drogas, tal como Doctor House, y heredera de su estilo de humor ácido. Más tarde, The Knick (2014-2015), aunque ambientada a principios del siglo XX, expone a un protagonista también adicto.

En 2005 se estrena Anatomía de Grey / Grey's Anatomy (TV) (ABC, 2005-) de Shonda Rimes que en 2020 comenzaría su decimoséptima temporada centrándose en el contexto actual y el trabajo de los profesionales sanitarios en la pandemia del coronavirus. Sin embargo, esta serie podría considerarse más un drama romántico que una serie médica, porque centra más su interés en las relaciones interpersonales de los médicos que en los pacientes.

Entre las series médicas actuales más populares se encuentran The Good Doctor (TV) (ABC, 2017), The Resident (TV) (Fox, 2018-) y New Amsterdam (TV) (NBC, 2018-).
The Good Doctor, desarrollada por David Shore (el productor de Doctor House) y Daniel Dae Kim, está basada en la serie surcoreana del mismo nombre de 2013. Su personaje principal, el doctor Shaun Murphy, es un joven residente que tiene autismo y síndrome de savant, lo cual también le ha valido la calificación de antihéroe. Esto implica que Shaun tiene dificultades intelectuales y emocionales graves, escasas habilidades de comunicación con sus colegas y pacientes, y otras particularidades tales como no entender el sentido del humor socialmente compartido, quedarse mirando el vacío y evitar el contacto visual; su memoria prodigiosa y la representación mental de la anatomía le distinguen de los demás colegas. Shaun realiza diagnósticos y propone tratamientos innovadores incluso cuando no parece haber ninguna solución disponible ${ }^{16-18}$.

En The Resident, los médicos residentes son representados como idealistas, aunque no siempre respetan las normas, mientras que los ejecutivos y los médicos seniors ocultan errores que se podrían considerar negligencia médica, incluso vinculadas a la corrupción hospitalaria. The Resident marca un punto de inflexión en el que no sólo aparecen errores profesionales, sino que los problemas institucionales y la consideración de la sanidad como un negocio también son temas centrales ${ }^{19}$.

New Amsterdam es la última serie médica estrenada en Estados Unidos, y su protagonista parece volver a las representaciones del médico-héroe en medio de un sistema sanitario que privilegia lo económico por sobre los cuidados médicos. La serie comienza con su primer día como jefe de medicina en el hospital público que da nombre a la serie. A partir de ese momento se pone al servicio de los pacientes y de los jefes de departamento con la muletilla "¿En qué puedo ayudar?". De alguna manera, actúa como el reverso de The Resident, donde los jefes son corruptos; aquí, el jefe enseña un camino a los demás profesionales: siempre el cuidado del paciente en primer lugar, dejando en segundo 
plano la burocracia o los intereses económicos. Los valores morales incorruptibles nos permiten avistar otro tipo de dilemas bioéticos: los que tienen que ver con los límites de cada profesional.

En el inédito contexto pandémico de 2020 nos interesó indagar las representaciones profesionales y los dilemas bioéticos de las series médicas enfocándolos en las epidemias retratadas, con el objetivo de analizar sus similitudes y diferencias y establecer puntos de interés para la docencia de la bioética.

Las series médicas tienen un gran atractivo para los estudiantes de las ciencias de la salud. De hecho, un altísimo porcentaje de estudiantes de medicina y de enfermería sigue las series médi$\operatorname{cas}^{20-22}$. Asimismo han mostrado ser un método pedagógico de interés ${ }^{23-25}$. Por otra parte, sabemos del interés que surge en relación con la figura del médico y su trabajo cotidiano, como en la utilidad de estas representaciones para los estudiantes ${ }^{20,21}$.

Tras realizar una búsqueda sistemática en las bases de datos disponibles (IMDB, Wikipedia) y bases de datos propias, recogimos todos los episodios de series médicas donde una epidemia sea el tema central (Tabla 1) y los temas bioéticos que pueden ser útiles para la enseñanza en ciencias de la salud.

Tabla 1: Epidemias en series médicas

\begin{tabular}{|c|c|c|c|c|c|c|c|}
\hline $\begin{array}{l}\text { Serie } \\
\text { (temporada } \\
x \text { episodio) }\end{array}$ & $\begin{array}{l}\text { Año del } \\
\text { episodio }\end{array}$ & $\begin{array}{l}\text { Enfermedades } \\
\text { representadas }\end{array}$ & \begin{tabular}{|l|} 
Repre- \\
sentación \\
de la \\
enfermedad
\end{tabular} & Fallecidos & $\begin{array}{l}\text { Representación de } \\
\text { los profesionales }\end{array}$ & \begin{tabular}{|l|} 
Temas \\
bioéticos \\
para la \\
docencia \\
\end{tabular} & $\begin{array}{l}\text { Cuarentena/ } \\
\text { aislamiento }\end{array}$ \\
\hline $\begin{array}{l}\text { Urgencias } \\
(8 \times 22 \text { y } \\
9 \times 01)\end{array}$ & 2002 & $\begin{array}{l}\text { Sospecha de } \\
\text { viruela. Virus } \\
\text { de la viruela } \\
\text { del mono. }\end{array}$ & $\begin{array}{l}\text { Peligrosa y de } \\
\text { rápida y letal } \\
\text { evolución. } \\
\text { Presentación } \\
\text { de pústulas } \\
\text { en dos niños. }\end{array}$ & $\begin{array}{l}\text { Sí. Una } \\
\text { niña. }\end{array}$ & $\begin{array}{l}\text { Abnegados. Tienen } \\
\text { que lidiar con una } \\
\text { enfermedad grave } \\
\text { y con la resistencia } \\
\text { de otros pacientes } \\
\text { y familiares a } \\
\text { quedarse en } \\
\text { cuarentena. }\end{array}$ & $\begin{array}{l}\text { Autonomía y } \\
\text { cuarentena. } \\
\text { Autonomía y } \\
\text { vacunación. }\end{array}$ & Sí. \\
\hline $\begin{array}{l}\text { Anatomía } \\
\text { de Grey } \\
(12 \times 02)\end{array}$ & 2005 & $\begin{array}{l}\text { Sospecha } \\
\text { de SARS. } \\
\text { Dermatitis. }\end{array}$ & $\begin{array}{l}\text { Escasa. } \\
\text { Se ve una } \\
\text { dermatitis } \\
\text { en la } \\
\text { espalda de } \\
\text { una de las } \\
\text { médicas, sin } \\
\text { evolución. }\end{array}$ & No. & $\begin{array}{l}\text { Egoístas, centrados } \\
\text { en sus propios } \\
\text { problemas. }\end{array}$ & $\begin{array}{l}\text { Influencia } \\
\text { de temas } \\
\text { personales en } \\
\text { el ejercicio de } \\
\text { la atención en } \\
\text { salud y en la } \\
\text { dinámica de } \\
\text { grupo. }\end{array}$ & Sí. \\
\hline $\begin{array}{l}\text { Doctor } \\
\text { House } \\
(1 \times 04)\end{array}$ & 2008 & Echovirus 11. & $\begin{array}{l}\text { Misteriosa. } \\
\text { Los } \\
\text { pacientes } \\
\text { son bebés. } \\
\text { Síntomas } \\
\text { leves. }\end{array}$ & $\begin{array}{l}\text { Sí. Un } \\
\text { bebé. }\end{array}$ & $\begin{array}{l}\text { House es } \\
\text { representado como } \\
\text { quien le interesa } \\
\text { más resolver el caso } \\
\text { que los propios } \\
\text { pacientes. Los } \\
\text { demás médicos se } \\
\text { preocupan por los } \\
\text { bebés y sus familias. }\end{array}$ & $\begin{array}{l}\text { Consenti } \\
\text { miento } \\
\text { informado. } \\
\text { Experiment } \\
\text { ación } \\
\text { con seres } \\
\text { humanos. } \\
\text { Autonomía. } \\
\text { Negación del } \\
\text { tratamiento. } \\
\text { Justicia. }\end{array}$ & Sí. \\
\hline
\end{tabular}

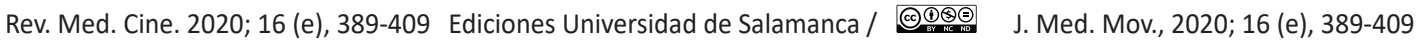




\begin{tabular}{|c|c|c|c|c|c|c|c|}
\hline $\begin{array}{l}\text { Serie } \\
\text { (temporada } \\
\text { x episodio) }\end{array}$ & $\begin{array}{l}\text { Año del } \\
\text { episodio }\end{array}$ & $\begin{array}{l}\text { Enfermedades } \\
\text { representadas }\end{array}$ & \begin{tabular}{|l|} 
Repre- \\
sentación \\
de la \\
enfermedad \\
\end{tabular} & Fallecidos & $\begin{array}{l}\text { Representación de } \\
\text { los profesionales }\end{array}$ & $\begin{array}{l}\text { Temas } \\
\text { bioéticos } \\
\text { para la } \\
\text { docencia } \\
\end{array}$ & $\begin{array}{l}\text { Cuarentena/ } \\
\text { aislamiento }\end{array}$ \\
\hline $\begin{array}{l}\text { The Good } \\
\text { Doctor } \\
(2 \times 10 \text { y } \\
2 \times 11)\end{array}$ & 2018 & $\begin{array}{l}\text { Sospecha } \\
\text { SARS. Virus } \\
\text { respiratorio. }\end{array}$ & $\begin{array}{l}\text { Peligrosa } \\
\text { y dañina, } \\
\text { de fácil } \\
\text { contagio } \\
\text { y rápida } \\
\text { evolución } \\
\text { (deriva en } \\
\text { muerte). }\end{array}$ & $\begin{array}{l}\text { Sí. Dos } \\
\text { (entre } \\
\text { ellos, un } \\
\text { profesional } \\
\text { sanitario). }\end{array}$ & \begin{tabular}{|l|} 
Dos profesionales se \\
ven afectados por la \\
enfermedad y uno \\
de ellos muere. Los \\
demás residentes \\
aprenden a realizar \\
procedimientos \\
complejos por \\
primera vez (una \\
cirugía y un parto) y \\
también contienen a \\
los demás pacientes \\
y familiares frente \\
a la cuarentena del \\
servicio de urgencias. \\
\end{tabular} & \begin{tabular}{|l|} 
Interferencia \\
de situaciones \\
personales de \\
los médicos en \\
la consulta. \\
Primeros \\
pasos como \\
profesional, \\
necesidad de \\
supervisión. \\
Cuidado de los \\
profesionales \\
sanitarios. \\
Muerte y \\
duelo. \\
\end{tabular} & Sí. \\
\hline $\begin{array}{l}\text { New } \\
\text { Amsterdam } \\
(1 \times 01)\end{array}$ & 2018 & $\begin{array}{l}\text { Sospecha de } \\
\text { virus de Ébola } \\
\text { y de virus de } \\
\text { Lassa. }\end{array}$ & $\begin{array}{l}\text { Peligrosa, } \\
\text { vinculada al } \\
\text { terrorismo. }\end{array}$ & No. & $\begin{array}{l}\text { Abnegados. Una de } \\
\text { las profesionales } \\
\text { entra a la sala de } \\
\text { aislamiento sin } \\
\text { protección frente } \\
\text { a una crisis del } \\
\text { paciente. } \\
\end{array}$ & Justicia. & Sí. \\
\hline $\begin{array}{l}\text { The } \\
\text { Resident } \\
2 \times 12\end{array}$ & 2019 & $\begin{array}{l}\text { Yersinia pestis } \\
\text { (peste negra). }\end{array}$ & $\begin{array}{l}\text { Desconocida } \\
\text { y peligrosa. }\end{array}$ & No. & \begin{tabular}{|l|} 
Los médicos jóvenes \\
son representados \\
como implicados con \\
su práctica. Una de \\
las profesionales de \\
enfermería entra a la \\
sala de aislamiento \\
sin protección frente \\
a una crisis de un \\
paciente. El director \\
del hospital parece \\
preocuparse más por \\
su propia imagen \\
que por los cuidados \\
de los pacientes.
\end{tabular} & Justicia. & Sí. \\
\hline
\end{tabular}

URGENCIAS: ¿VIRUELA EN EL AÑO 2002?

En los episodios 8x22 "Lockdown" y su continuación en 9x01 "Chaos Theory", la acción gira en torno a la amenaza que supone una enfermedad como la viruela, erradicada desde 1940. Habiendo demorado en atender a dos niños en el servicio de urgencias por estar colapsado, el primer médico que nota la presentación de la enfermedad en los hermanos (pústulas firmes, con lecho profundo, mismo desarrollo, distribución centrífuga excepto en el tronco) ordena ponerles mascarillas, cerrar todo el servicio y dejar a los pacientes, familiares y profesionales en cuarentena (Foto 1 ). 


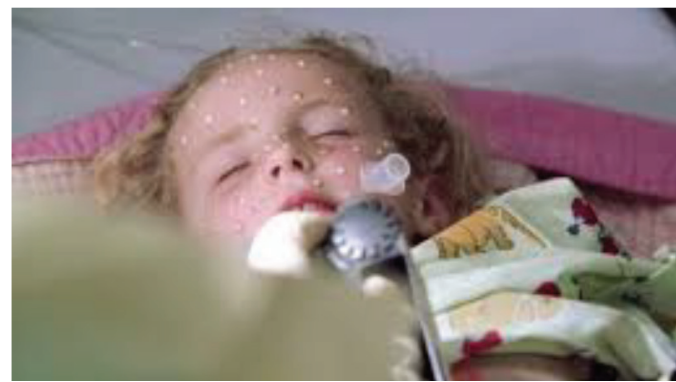

Foto 1. Representación del posible caso de viruela en Urgencias.

La familia había estado en África recientemente. Los riesgos son evidentes: es una enfermedad infecciosa grave, se transmite por vía aérea, y tiene un alto riesgo de muerte. El Departamento de Sanidad aparece a los pocos minutos: ordena proseguir con la cuarentena y apagar el aire acondicionado para evitar que la enfermedad se propague. Todas las demás decisiones corren por cuenta de los médicos que se quedaron en el servicio; mientras tanto, la jefa de urgencias no puede entrar al hospital por precaución. Cuando la niña tiene una crisis y muere delante de su familia, el clima se torna lúgubre. Todavía queda confirmar el diagnóstico y salvar al hermano. El médico le promete que no lo dejará morir. Cuando minutos más tarde el niño tiene una crisis respiratoria, el médico se quita las gafas y la máscara protectora para salvarlo, sosteniendo el ideal del médico-héroe de las primeras series médicas.

Mientras tanto, en la sala de espera, los pacientes no pueden irse por la cuarentena dictaminada y comienzan a organizar una demanda colectiva contra el jefe de sanidad por "encarcelamiento ilegal con daños emocionales". El médico-héroe interrumpe el descalabro y se sincera informándoles: "esta mañana vino una niña con síntomas que parecían viruela. Murió enseguida. Su hermano está grave. No sabemos qué es ni cómo se infectaron. Nadie ignora sus derechos civiles. Solo intentamos protegerlos".

Cuando llega nueva información del laboratorio sobre el virus -se trata de la misma mutación que en el Congo, lo cual implica una gravedad inusitada- ordenan evacuar a todo el hospital. En esta evacuación de emergencia se producen una serie de incidentes ligados con el descuido profesional. A su vez, el conocimiento de nuevos detalles sobre el virus permite empezar a vacunar a todos por precaución, aunque hay quienes se resisten a los quince pinchazos. Los médicos que tenían síntomas deben quedarse en cuarentena dos semanas más por precaución.

La rápida resolución del caso a partir del dictamen: "no era viruela, era viruela del mono", para el cual existe un tratamiento relativamente sencillo, permite cerrar el episodio con tranquilidad, pero sin saber demasiado sobre el duelo de la familia y la cura del hijo.

\section{ANATOMÍA DE GREY: SOLO IMPORTA EL ROMANCE}

En 12x02 "Walking Tall" la doctora April Kepner vuelve de un viaje de tres meses en solitario, escapándose de su matrimonio, y una de sus compañeras nota que tiene un sarpullido en la espalda. Inmediatamente se pone una mascarilla y ordena que Kepner se aísle. Ella cree que están exagerando, pero la jefa puntualiza los síntomas: tiene lesiones, tos, fiebre y ha estado recientemente en Oriente Medio. Con la sospecha de estar frente a un virus SARS en su primer día como responsable del hospital, Bailey dictamina: "hoy no habrá epidemia", y manda a Kepner a una sala de aislamiento.

A partir de ese momento, los médicos se desplazan hasta donde está Kepner para conversar sobre su posible diagnóstico y, fundamentalmente, para hablarle de los problemas personales de cada uno. Como las paredes son 
plásticas y Kepner se siente bien, la sala de aislamiento se convierte en lugar de procesión de sus compañeros y sus dramas personales. Ella parece preocuparse más por recibir la visita de su pareja que por su posible enfermedad. Luego de unas horas, su marido se acerca de manera recelosa y no muestra señales de querer hablar de su fracaso matrimonial. En una segunda visita discuten sobre los motivos por los cuales se alejaron (Foto 2).

Las horas pasan lentamente para Kepner, mientras sigue recibiendo visitas de sus compañeros que parecen seguir interesándose más en exponer sus problemas del corazón que en desentrañar qué enfermedad padece. Cuando su marido se acerca por tercera vez, le informa que el laboratorio concluyó que no tiene un virus respiratorio sino una dermatitis y que puede irse. Ella hace un discurso acerca de cómo luchará por su amor y el interés por la enfermedad queda nuevamente relegado.

\section{DOCTOR HOUSE: EL ACERTIJO POR SOBRE LOS PACIENTES}

Gregory House es reconocido por sus habilidades médicas y detectivescas - de hecho, ha sido comparado con Sherlock Holmes en múltiples ocasiones. Al ser jefe del Departamento de Diagnóstico, llegan hasta él los casos extraños para los cuales no hay respuesta. Conocido por su reticencia a hablar con los pacientes, House tiene como muletilla la afirmación "todo el mundo miente" y sugiere no distraerse con lo que los pacientes dicen, sino concentrarse únicamente en sus enfermedades.

En 1x04 "Maternity" no le llega un caso dificil para consulta sino que es él quien sale de su despacho a buscar un acertijo en los pasillos del hospital. Cuando se entera que hay dos bebés con síntomas similares en neonatología, House afirma que "tenemos una infección corriendo por el hospital". La directora médica se asusta frente a este panorama, cierra la sala de maternidad y comienza a desviar pacientes a otros

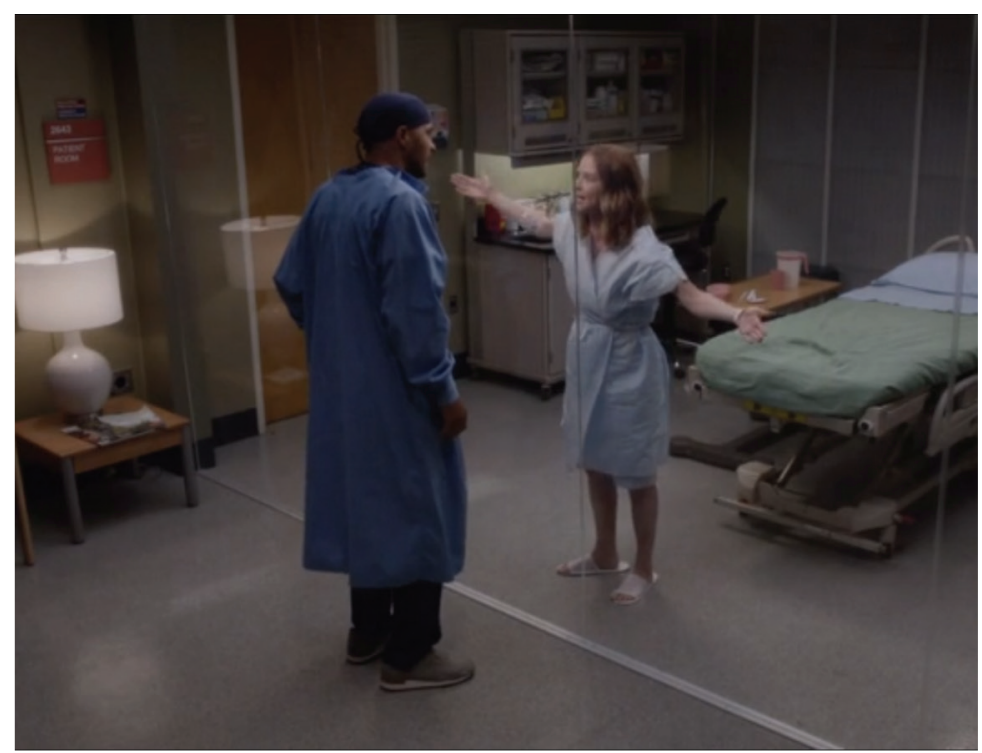

Foto 2. Discusiones de pareja en la sala de aislamiento en Anatomía de Grey. 


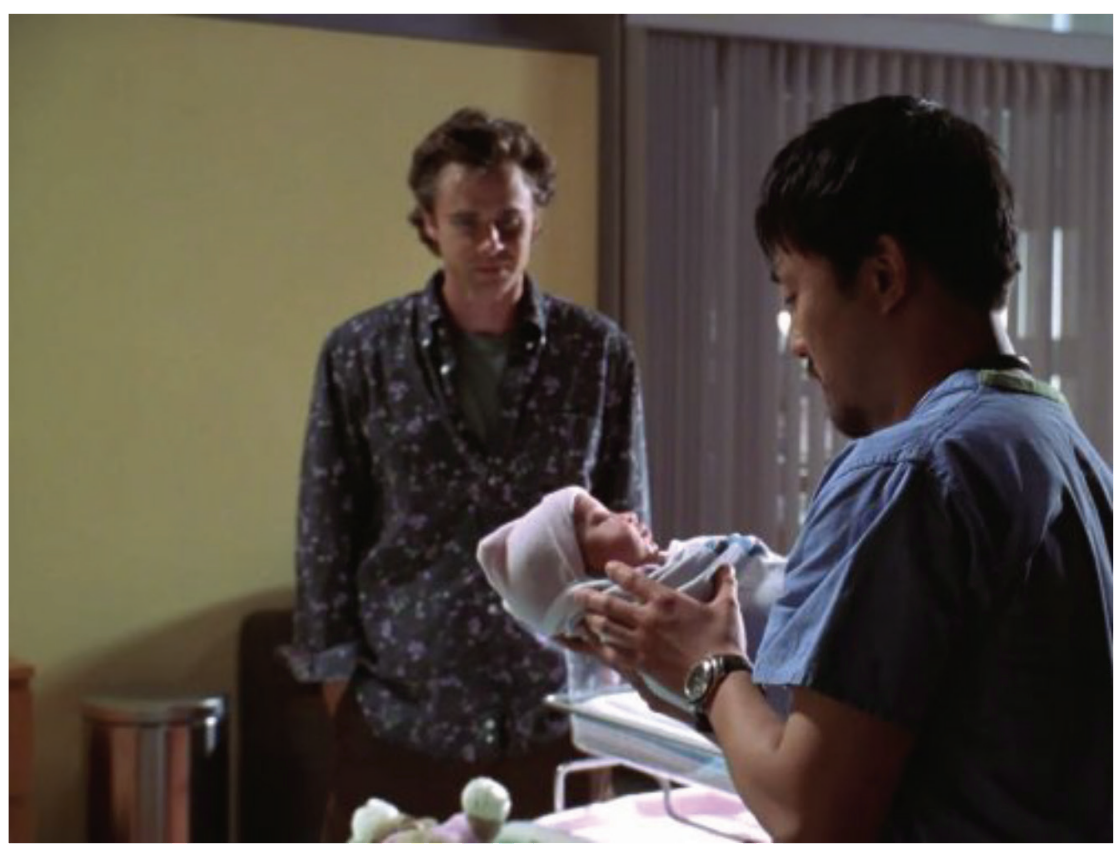

Foto 3. Uno de los bebés que manifiesta los síntomas que interesan a House.

hospitales. A los pocos minutos, hay tres bebés enfermos, y uno más empieza a mostrar los mismos síntomas, fiebre e hipotensión (Foto 3). Si estos síntomas prosiguen, House considera que la muerte es inminente. Su interés por descubrir qué está pasando le lleva a preguntarse qué tienen en común. A través de sus interlocutores (la directora Cuddy, su amigo Wilson y los espectadores) plantea la pregunta: chay diferencias entre una epidemia y una coincidencia? ¿El hecho de que tres bebés tengan fiebre permite hablar de una epidemia en un hospital?

La representación de House como alguien cínico a quien solo le importa desentrañar el diagnóstico, sin ocuparse de sus pacientes, está muy presente en las primeras temporadas de la serie. En este episodio esto se lleva al extremo, sobre todo en los dilemas bioéticos que se suscitan frente al desconocimiento de la enfermedad.
Como no hay tiempo para esperar los resultados de los análisis, House ordena comenzar un tratamiento con diferentes antibióticos, pero uno de ellos daña los riñones de dos de los tres bebés. Para poder confirmar cuál es el medicamento erróneo, House propone dejar de darle un antibiótico diferente a cada bebé, sin notificar a sus padres del cambio en el tratamiento, y esperar a ver qué sucede.

Semejante intención de experimentación con seres humanos sin considerar su bienestar y en ausencia de su consentimiento informado para poder seguir adelante con el tratamiento sería impensable en cualquier hospital. Sin embargo, cuando House alega que este cambio de medicación podría salvar a los demás bebés, la directora médica aprueba el procedimiento. Sin lugar a dudas se privilegia el bien común por encima del bien individual y, cuando uno de los bebés muere, 
House prosigue con la búsqueda del diagnóstico. Son los médicos residentes de su equipo quienes se ven afectados, sobre todo Cameron, encargada de comunicar la noticia a su familia.

La resolución del caso sigue por la vía de excepciones a los procedimientos. House hace una autopsia del bebé que había fallecido (sin ninguna autorización, podemos suponer) y concluye que no se trata de una bacteria sino de un virus. Al estudiar un bebé sano, nuevamente sin consentimiento, puede descartar las distintas hipótesis y concluir que se trata de un echovirus 11. Encontrar la fuente de la enfermedad es el nuevo desafío para House y pronto tendrá la pista que necesita: mientras observa los movimientos en Maternidad, nota que una de las enfermeras reparte ositos de peluche mientras se suena la nariz, visiblemente resfriada.

Es interesante mencionar que otras epidemias se representan en $1 \times 19$ "Kids" y $3 \times 18$ "Airborne", aunque sin demasiados conflictos bioéticos. En el primer caso, Foreman conduce un diagnóstico a contrarreloj de 2500 personas que estuvieron presentes en una competición de natación donde una de las nadadoras podría tener meningitis bacteriana. Como hay recortes en el área de enfermería del hospital, todos los médicos deben hacer el diagnóstico rápido de los pacientes y ordenar su salida del hospital. El caso se resuelve declinando este diagnóstico y focalizándose en otros problemas.

En "Airborne", Cuddy y House vuelven en un avión desde Singapur y un paciente comienza a descompensarse en primera clase. Presenta vómitos y eccemas cutáneos. Cuddy teme por un brote epidémico pero House niega esta posibilidad. Sin embargo, cuando una segunda pasajera comienza a mostrar los mismos síntomas, se preocupa y empieza a diagnosticarles con los recursos que dispone en ese momento. Pronto el avión comenzará a plagarse de pasajeros con los mismos síntomas, incluida Cuddy. House razona con otros pasajeros del avión para resolver qué es lo que está sucediendo: el pasajero de Singapur padece síndrome de descompresión contraído por subir a alturas extremas luego de haber buceado en la profundidad del océano el día anterior. Todos los demás pasajeros tienen un brote de histeria que favorece la repetición de síntomas. Lo más interesante del episodio es presenciar el razonamiento deductivo de House.

\section{THE GOOD DOCTOR: APRENDIENDO CON EL ANTIHÉROE}

Los episodios 2x10 y 2x11 "Quarantine" funcionan a la manera de un unitario de suspense. En los primeros minutos del primer episodio ingresan dos pacientes en urgencias y los paramédicos informan a los médicos que ambos son trasladados desde el aeropuerto y provienen del mismo vuelo desde Malasia. El primero es un varón, de unos 30 años, que llega inconsciente, con hipoxemia, presencia de sibilancias pulmonares y resistencia significativa de las vías respiratorias al flujo aéreo. Tras una primera reanimación cardíaca en el aeropuerto, el paciente presenta una parada cardíaca en el hospital. El segundo paciente es una mujer, también joven, aquejada de dolor torácico y dificultades respiratorias, que se acompañan de fiebre. La hipótesis del diagnóstico surge al tratar al primer paciente: "podría ser un síndrome respiratorio por una neumonía vírica". El joven fallece a los pocos minutos. Como ambos tienen erupciones en el área cervical, además de fiebre y síntomas respiratorios, los médicos concluyen que tienen la misma enfermedad. La neumomía obliga a poner en cuarentena a los profesionales sanitarios del servicio de urgencias.

Los médicos intentan conocer el diagnóstico de una manera detectivesca, desentrañando un misterio a contrarreloj. Cuando descubren que los dos pacientes viajaban en el mismo avión pero no habían tenido contacto directo entre sí, comienzan a preocuparse pensando que la 
forma de contagio podría ser por vía aérea, lo cual resulta una amenaza mucho más peligrosa y veloz (Foto 4).

El progreso del virus está explicado en los primeros minutos del episodio: primero se manifiesta una erupción cervical, luego aparece la fiebre, surge la tos, sobreviene una afectación respiratoria y por último el colapso con una insuficiencia respiratoria aguda. La sensación preocupante de todos los profesionales se multiplica al pensar que el progreso de la infección vírica es rápida: el primer paciente pasa por todas las fases y muere en menos de 24 horas. La primera decisión es aislar a los pacientes contagiados en cabinas plásticas de presurización negativa, pero cuando la jefa de guardia confirma que el contagio pudo ser por vía aérea propone una cuarentena en todo el servicio de urgencias. Seguidamente, comunica la situación al director del hospital, quien notifica al Centro de Control y
Prevención del Departamento de Salud Pública, por si llegara a ser necesario localizar a los demás pasajeros del avión. Luego, se realiza una reunión de trabajo en el mismo hospital, con el director y las autoridades de sanidad. La necesidad de realizar acciones coordinadas aparece en primer plano.

El protagonista de la serie aporta sus particularidades a esta epidemia. Más allá de ser un residente de segundo año, Shaun Murphy necesita la guía de sus colegas y jefes en distintas ocasiones. Se representan insistentemente sus dificultades de concentración frente al ruido de una de las luces de la sala de guardia y frente a su esquema horario previamente establecido ("siempre almuerzo a las 14, son 14:15", "mi guardia terminó hace 37 minutos. Tengo cosas importantes que hacer"). El ruido de la luz hace que Shaun tenga una crisis al final del primer episodio. En el momento en el cual se

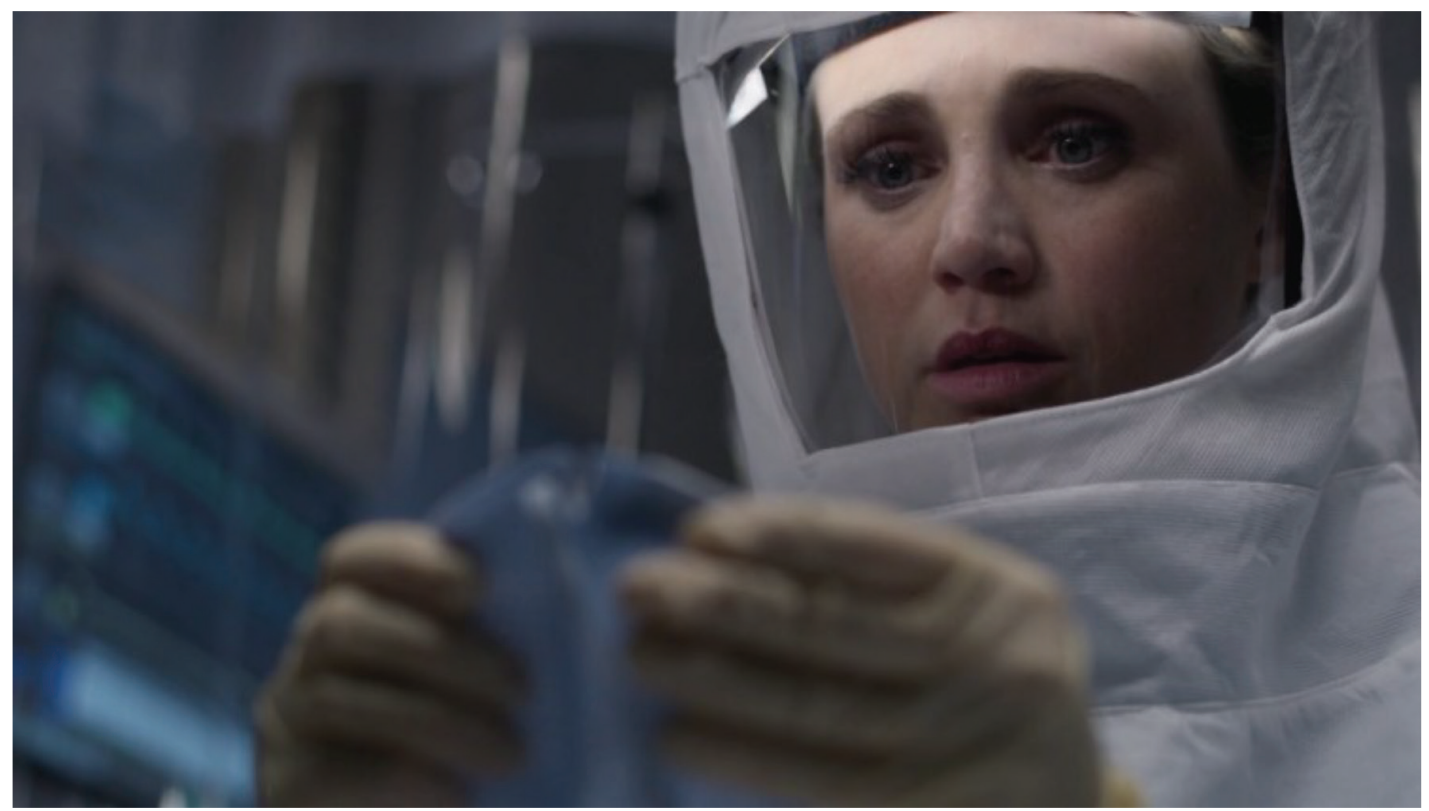

Foto 4. Los profesionales de The Good Doctor se visten con trajes de protección de alta seguridad. 
necesita su respuesta para atender a los pacientes en forma urgente -y ayudar a su colega, que requiere de su colaboración para realizar una cirugía- Shaun se tapa los oídos con las manos y se deja caer al suelo, donde permanece con la mirada perdida. Una de sus compañeras de residencia es quien da la clave para que se recupere en el comienzo del segundo episodio, indicándole a la enfermera que no debe gritarle y que le tiene que hablar de la cirugía para que vuelva en sí. Enajenado y aún en el suelo, Shaun comienza a imaginarse las representaciones anatómicas que le permitirán hacer la cirugía y da con la clave del caso. Asimismo, cuenta con la ayuda de otro de sus compañeros, que rompe la lámpara que causa el ruido. Estas dificultades que tiene Shaun -en este episodio y en los demásnos permiten identificarnos con el personaje y aprender con él ${ }^{26}$.

La rápida resolución posterior, el desentrañamiento del diagnóstico, la recuperación de la médica infectada, y el "final feliz" en cada una de las historias de la trama parecen obedecer más a los tiempos del audiovisual y a un "milagro de Navidad" que al desarrollo de una epidemia real.

\section{NEW AMSTERDAM: UNA EPIDEMIA COMO ASUNTO DE SALUD Y DE SEGURIDAD NACIONAL}

En 1x01 "Pilot", New Amsterdam presenta la historia de un joven africano que llega solo al aeropuerto de Nueva York y se sube a un taxi camino al Hospital público que da nombre a la serie. El servicio de urgencias está abarrotado y se desmaya en la larga espera para que lo atiendan. En ese momento, indagan en sus cosas para saber quién es y de dónde viene. Cuando encuentran su tarjeta de embarque del avión, la médica a cargo del servicio de urgencias advierte para que los demás profesionales se alejen inmediatamente del paciente y se coloquen mascarillas, mientras llama al director médico del hospital: "tenemos un paciente que proviene de Liberia y tiene todos los síntomas de malaria, fiebre de Lassa, tuberculosis o Ébola". Lo primero que hacen es llamar al Centro de Control y Prevención del Departamento de Salud Pública y al alcalde de la ciudad para indagar si hay sospechas del virus de Ébola.

El paciente es aislado pero el asunto se convierte en un tema de seguridad nacional. Inmediatamente, agentes del FBI se presentan en el hospital y le dicen al director que un agente de ISIS infectado con el virus de Ébola iba a ser enviado a Nueva York. El paciente, sospechoso de terrorismo, cuenta amablemente la historia a los agentes: "Un hombre vino a mi pueblo. Estaba enseñando el dinero que había hecho en Estados Unidos vendiendo gorros kufi y dashikis en Times Square. Se ofreció a darme prendas para vender y un billete de avión si le daba la mitad de lo que ganase. Me llevó a ver a un médico para una vacuna para el viaje". Queda claro que el joven no es un terrorista pero deben esperar a los resultados de los análisis para saber qué tiene.

Cuando el paciente sufre hemoptisis y empieza a ahogarse y escupir sangre, la médica a cargo se apresura para ponerse el traje de protección especial pero no llega a tiempo. Rompe entonces el protocolo al no ponerse el casco sino una mascarilla quirúrgica simple, entra en la sala de aislamiento y ayuda al paciente con la guía del director del hospital. Minutos más tarde, notan que tiene su guante roto, por lo cual debe quedarse aislada con él. La situación se resuelve cuando se confirma que el joven había recibido una inyección con el virus de Lassa, que es similar al Ébola, pero no es mortal y puede ser tratado con medicación antivírica que ya le habían dado. Debido a la intermediación del director del hospital -en su papel de héroe-los agentes de seguridad dejan que el paciente se recupere en la habitación (Foto 5). 


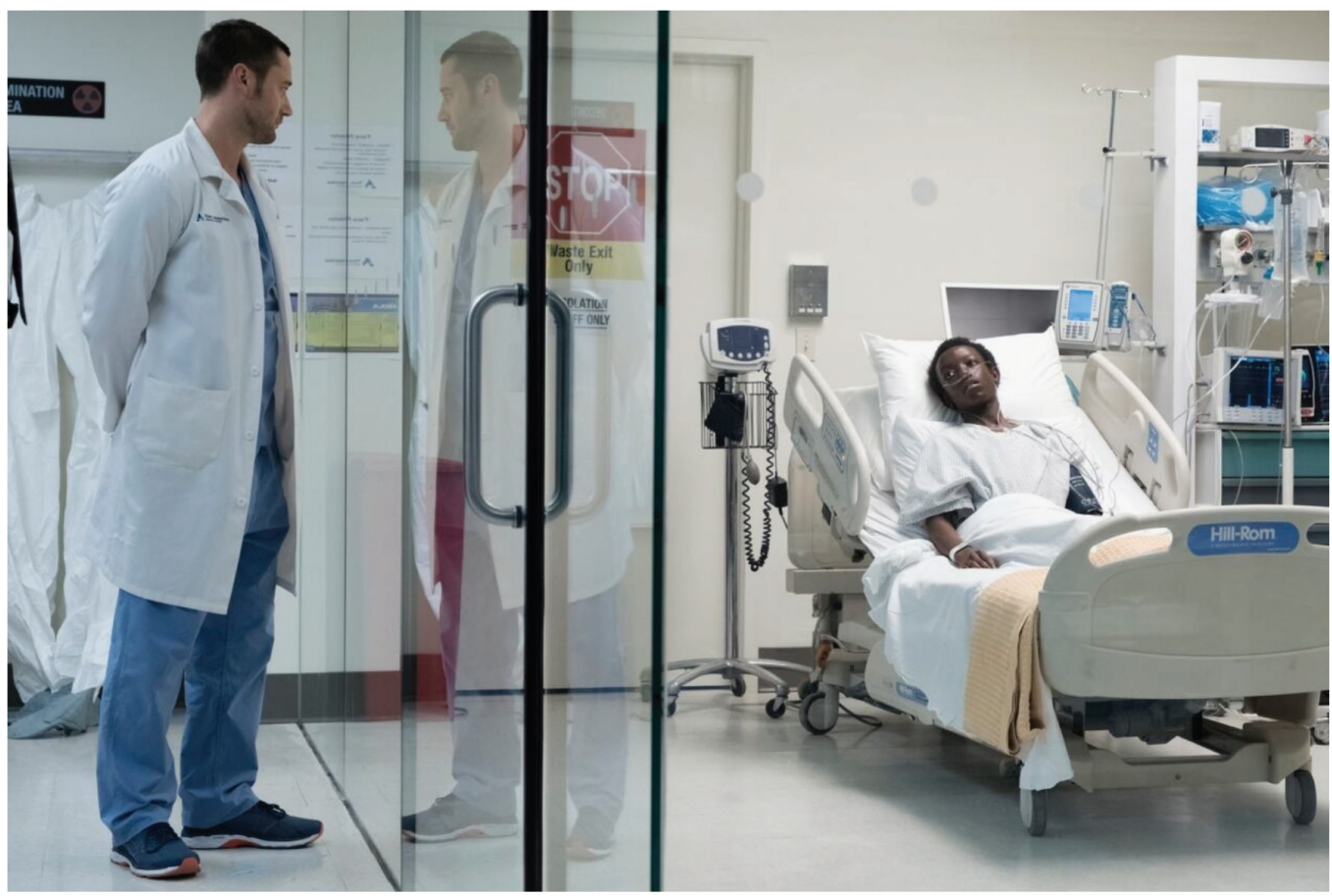

Foto 5. El director del hospital de New Amsterdam, preocupado por el joven africano.

THE RESIDENT: ENTRE EL INTERÉS PERSONAL Y EL CUIDADO DE LOS PACIENTES

El comienzo del episodio 2x12 "Fear Finds a Way" nos pone sobre aviso de una epidemia: " $L a$ mitad de Atlanta tiene gripe y la otra mitad cree que la tiene". Las salas de urgencias están abarrotadas de pacientes con tos, fiebre y dolor torácico. La representación de un contagio a través de objetos y estornudos nos recuerda a las primeras imágenes de Doctor House, donde se representaba gráficamente el momento de contagio de la enfermedad.

Un médico nuevo, experto en enfermedades infecciosas, llama la atención de las personas que se encuentran en urgencias: "Gente, estamos en 1918, ¿sí? No hay microondas, Babe Ruth va a lanzar la bola y la expectativa de vida bajó 12 años. ¿Alguien sabe por qué? ¿Fue la Primera Guerra Mundial? No. La guerra mató a nueve millones. La gripe española mató a más de 50 millones. ¿Ahora me prestan atención?" Este discurso impacta en la gente y admiten entonces la espera para el proceso de selección. Quienes están vacunados de la gripe son enviados a sus casas -ya que sería peor contagiarse de algo en el hospital-.

Una de las personas que aguardaba en urgencias se desmaya y los médicos recuentan sus síntomas: "tiene petequias y fiebre. No responde al tratamiento". Surge entonces la hipótesis: es posible que se trate de un tipo de gripe que aún no se conoce. Para evitar que se propague la enfermedad, se pone a la paciente en una habitación de aislamiento, lo cual provoca el reclamo del director del hospital: "Deben llamar al director antes de iniciar una cuarentena... sean discretos: si hay rumores de una epidemia, se generará pánico" (Foto 6). El cuidado de su imagen por encima de los pacientes no es nuevo y refleja su interés por los temas económicos y el rédito personal ${ }^{19}$. 


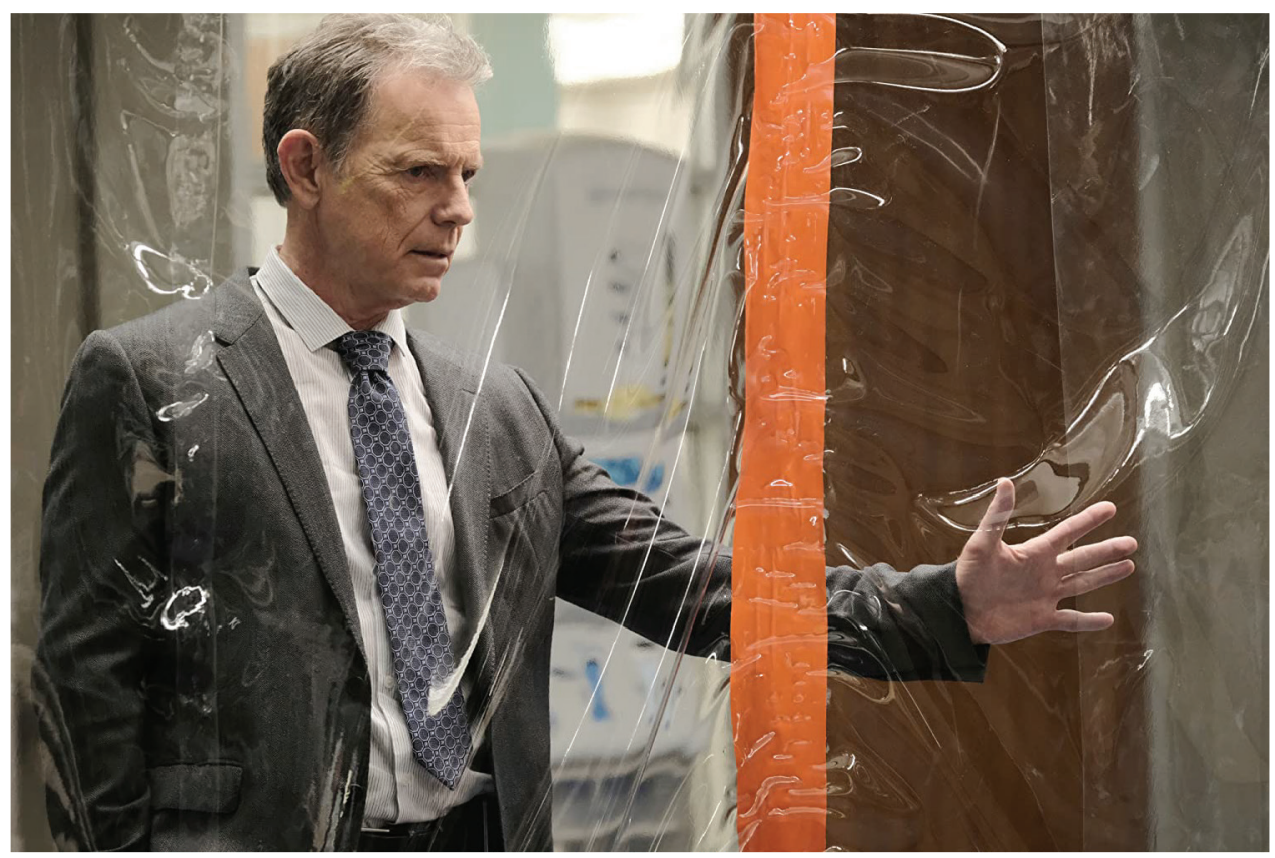

Foto 6. El director del hospital en The Resident, más preocupado por su imagen y negocios que por el cuidado de sus pacientes.

En un primer momento, los médicos entran casi sin protección a la habitación aislada. Cuando el estado se agrava, comienzan a extremar los cuidados. Cuando en urgencias detectan que otro paciente tiene erupciones, dan mascarillas a todos y el tema comienza a circular en las redes sociales. El director del hospital tiene entonces la intención de trasladar a los dos pacientes a un hospital especializado en enfermedades infecciosas, pero esto podría matarlos. Nuevamente, no se implica en el bienestar de los pacientes. Mientras tanto, un médico y una enfermera van a la cárcel a buscar el paciente cero, que manifieste los mismos síntomas (erupción en cualquier lugar del cuerpo, inflamación del cuello o la ingle, y fiebre elevada) y notifican al Centro de Control y Prevención del Departamento de Salud Pública.

Frente a una crisis respiratoria de uno de los pacientes en aislamiento, la enfermera entra sin llegar a ponerse todo el traje, implicándose en su mejoría pero quedando expuesta, razón por la cual debe mantenerse en aislamiento. Como no ha habido hemorragia cerebral, la convulsión debe haber sido por la infección. El diagnóstico llega, como en todos los casos anteriores, rápidamente: Yersinia pestis, el agente etiológico de la peste negra. Es resistente a todos los antibióticos excepto a la colistina. Administran rápidamente la medicación y salen en búsqueda del paciente cero, llegando a la casa de la pareja del paciente cuando ésta tiene una crisis. Uno de los personajes resume el final feliz: "Todos van a sobrevivir".

CONCLUSIONES: LA REALIDAD REPRESENTADA EN LAS SERIES MÉDICAS

Las series médicas son atractivas para estudiantes y un método pedagógico de interés en las 
ciencias de la salud. El hecho de que varias series médicas retraten epidemias puede incrementar la motivación e interés de los estudiantes y el desarrollo de un pensamiento crítico respecto de las cuestiones bioéticas involucradas en estas situaciones. Teniendo en cuenta que la pandemia de coronavirus aún no ha finalizado, el método de aprendizaje con cine y series puede servir para analizar tales aspectos en el presente y en un futuro próximo.

Investigaciones previas sugieren que las series médicas influencian positivamente a los estudiantes de ciencias de la salud, y que pueden ser utilizados como estrategias de enseñanza especialmente como instrumentos para la mejora en las herramientas de la comunicación médico-paciente así como en los modelos positivos como negativos de conducta médica ${ }^{27}$. En el panorama de series que hemos analizado, tenemos representados en su mayor parte médicos-héroes (Urgencias, New Amsterdam, los jóvenes de The Resident), aún con el peligro que conlleva considerar a los profesionales sanitarios como héroes o mártires. En la pandemia del coronavirus fue muy criticada esta representación (e incluso los "aplausos sanitarios" de todos los días a las 20:00 h), porque invisibilizaban la desprotección sufrida frente al contagio y las condiciones laborales de los profesionales.

También se representan antihéroes, Doctor House y The Good Doctor, aunque por distintas razones: House atropella los derechos y resguardos para los pacientes, Shaun Murphy aprende a partir de las limitaciones de su autismo. Y por último, médicos más preocupados por el devenir de sus romances que por el desarrollo de enfermedades potencialmente mortíferas (Anatomía de Grey).

Asimismo, el sistema sanitario también juega un papel importante en estas representaciones. En las series actuales como The Resident y New Amsterdam se advierte que el interés por las cuestiones económicas es más importante que el cuidado de los pacientes.
En cuanto a la atención de las epidemias, es notable que en los seis episodios analizados surge rápidamente la idea del aislamiento y la cuarentena obligatoria, así como también la necesaria protección de los profesionales de la salud a través de trajes y equipamientos especiales. Sin embargo, es interesante mencionar que en dos episodios (Urgencias y The Good Doctor) la cuarentena ocasiona resistencia en las personas que se encuentran esperando en el servicio de urgencias, principalmente debido a la desinformación.

En cinco de los seis de los episodios los profesionales se infectan y se convierten en pacientes (Urgencias, Anatomía de Grey, New Amsterdam, The Resident y The Good Doctor), y en The Good Doctor, uno de ellos muere. Es importante mencionar que el impacto de este tipo de enfermedades infecciosas en los profesionales de la salud incluye también aspectos ligados con el estrés y el burn-out ${ }^{28}$.

En The Resident y New Amsterdam se representa a profesionales que están dispuestos a sacrificarse frente a la crisis de un paciente: en el primer caso, una enfermera entra a la sala de aislamiento sin traje de protección, y en el segundo, la médica a cargo entra con el traje mal puesto, con mascarilla quirúrgica, y uno de los guantes se le rompe en una maniobra. Además de puntualizar sobre su dedicación y su entrega, es necesario introducir la pregunta sobre los protocolos de emergencia: ¿no se debe tener a alguien siempre preparado con el EPI puesto, en lugar de tener que completar todo el procedimiento frente a la crisis de un paciente?

En los tres casos de las series más recientes (The Good Doctor, New Amsterdam, The Resident), se notifica inmediatamente al Centro de Control y Prevención del Departamento de Salud Pública y se realizan acciones coordinadas junto con el gobierno (al igual que en Urgencias). En New Amsterdam se agrega la variable de la conspiración y el terrorismo. 
La representación de la enfermedad como agente externo se repite en cinco de las seis series analizadas: en Urgencias proviene del África, en Anatomía de Grey y New Amsterdam, de Medio Oriente, y en The Good Doctor, de Asia. En The Resident el origen de la enfermedad aparece vinculado a Yosemite, donde una de las pacientes hace senderismo, y en Doctor House no hay referencias más allá del hospital.

Las cuestiones bioéticas que pueden analizarse en actividades docentes de ciencias de la salud se vinculan principalmente con las restricciones de la autonomía que supone una cuarentena (con conflictos que llegan a la agresión en Urgencias y The Good Doctor) y con la implicación de los profesionales de la salud, ya sea por infectarse por no tener los suficientes cuidados, o por el estrés que puede suponerse que sufren por estas situaciones. Es interesante que en ningún caso se represente uno de los aspectos más oscuros de la epidemia del coronavirus, respecto de la justicia: la saturación del sistema sanitario, la existencia del proceso de selección en los servicios de urgencias y unidades de cuidados intensivos, y la imposibilidad de distribuir recursos de igual manera a todos los pacientes.

Sería interesante proseguir con esta investigación en dos direcciones: volviendo hacia las series clásicas, aun cuando haya problemas para encontrar los episodios, para indagar si existen representaciones sobre epidemias y, si no existen, hipotetizar por qué; y trabajar con las nuevas temporadas de Grey's Anatomy y The Good Doctor, que tomarán sin duda el contexto del coronavirus.

Una última pero necesaria reflexión respecto de la adecuación de las representaciones sobre las enfermedades y epidemias. Algunos estudios señalan que las series médicas pueden influenciar negativamente a los estudiantes debido a que podrían ser irreales o potencialmente dañinas ${ }^{29}$. El argumento radica en la lejanía de las series respecto a la veracidad de los procedimientos hospitalarios y de la práctica profesional. Nunca forma parte de nuestras investigaciones la evaluación de esta adecuación a la "realidad", sin embargo, se ha de notar que en todos los casos las epidemias de las series de televisión no atienden a más de tres pacientes. En este sentido, no hay servicios sanitarios colapsados ni un verdadero peligro para la población más allá del hospital donde se hace la cuarentena. En todos los casos la resolución es rápida, sobre todo por los tiempos de la ficción televisiva. Teniendo en cuenta estas anotaciones, volvemos a considerar que más importante que la adecuación del guión es la plausibilidad de una situación compleja, para poder estudiarla en detalle ${ }^{30}$, y que se pueden incorporar estas consideraciones en una actividad docente que se focalice más en las cuestiones bioéticas.

\section{REFERENCIAS}

1. Chory-Assad RM, Tamborini R. Television doctors: An analysis of physicians on fictional and non-fictional television programs. J Broad Electr Media. 2001;45(3):499-521.

2. Cambra Badii I, Guardiola E, Baños JE. From Marcus Welby, M.D. to The resident: The changing portrayal of physicians in TV medical dramas. J Med Mov. 2020;16(2): 87-102.

3. Gerbner G, Gross L, Morgan M, Signorielli N. Special report: Health and medicine on television. $\mathrm{N}$ Eng J Med. 1981; 305(15):901-4.

4. Gerbner G, Morgan M, Signorielli N. Programming health portrayals. In Pearls D, Bouthilet L, Lazar J, editors. Television and behavior: Ten years of scientific progress and implications for the eighties, Volume 1. Rockville, MD: National Institute of Mental Health; 1982.

5. Kalisch PA, Kalisch BJ. Sex-role stereotyping of nurses and physicians on prime-time television: $A$ dichotomy of occupational portrayals. Sex Roles 1984;10(7-8):533-53.

6. Malmsheimer R. Doctors only: The evolving image of the American physician. New York: Greenwood Press; 1988. 
7. Turow J. Television Entertainment and the U.S. Health Care Debate. The Lancet. 1996; 347(9010):1240-3.

8. Holoweiko M. Good news-the pedestal is gone. Med Econ. 1998; 75(20):54-56. 63, 67.

9. Pfau M, Mullen LJ, Garrow K. The influence of television viewing on public perceptions of physicians. J Broad Electr Media. 1995;39:441-58.

10. Foss K. "When we make mistakes, people die!": constructions of responsibility for medical errors in televised medical dramas, 1994-2007. Commun. Q. 2011;59(4): 484-506.

11. Lim E, Seet R. In-house medical education: Redefining tele-education. Teach Learn Med. 2008;20(2):193-5.

12. Cambra Badii I, Michel Fariña JJ. House y la cuestión de la verdad. Bioética y psicoanálisis. Buenos Aires: Letra Viva; 2017.

13. Cambra Badii I. La Narrativa Cinematográfica como vía de acceso a la complejidad en Bioética. Tesis de Doctorado en Psicología. Buenos Aires, 2014.

14. Jerrentrup A, Mueller T, Glowalla U, Herder M, Henrichs N, Neubauer A, Schaefer JR. 2018. Teaching medicine with the help of "Dr. House". PloS One, 13(3), e0193972.

15. Strauman E, Goodier BC. Not your grandmother's doctor show: A review of Grey's Anatomy, House, and Nip/Tuck. J Med Humanities. 2008;29:127-31.

16. Baños JE, Cambra Badii I, Guardiola E. A physician with autism in a TV series. The Lancet Neur. 2018;17(10):844.

17. Cambra-Badii I, Baños J. ¿Un médico con autismo en la televisión? Enseñanzas de The Good Doctor. Rev Med y Cine. 2018;14(4):273-83.

18. Cambra Badii I, Pinar A, Baños JE. The Good Doctor and bioethical principles: a content analysis. Educ Med. 2020 epub.

19. Cambra Badii I, Baños JE. A walk on the wild side of medicine: a review of The Resident. Educ Refl Prac. 2018;2:52-65.
20. Czarny M, Faden R, Nolan M, Bodensiek E, Sugarman J. Medical and nursing students' television viewing habits: potential implications for bioethics. AJOB. 2008;8(12):1-8.

21. Weaver R, Wilson I. Australian medical students' perceptions of professionalism and ethics in medical television programs. BMC Med Educ 2011;11(1):50.

22. Williams D J, Re D, Ozakinci G. Television viewing habits of preclinical UK medical undergraduates: Further potential implications for bioethics. AJOB Empirical Bioethics 2014; 5(2):55-67.

23. Goodman K. Medical education: Imagining doctors: Medical students and the TV medical drama. Virtual Mentor 2007; 9(3):182-7.

24. Arawi T. Using medical drama to teach biomedical ethics to medical students. Med Teac. 2010;32(5):205-10.

25. Law M, Kwong W, Friesen F, Veinot P, Ng S. The current landscape of television and movies in medical education. Perspect Med Educ. 2015;4(5):218-24.

26. Cambra Badii I, Baños JE. Una epidemia en la serie médica The Good Doctor: aprendiendo con quienes aprenden. En: Pinto Bustamante B, Ramirez F, editores. Bioética, cine y pandemia. Colombia: Centro Editorial del Departamento de Bioética de la Universidad El Bosque. En prensa, 2020.

27. Hirt C, Wong K, Erichsen S, White J. Medical dramas on television: a brief guide for educators. Med Teac. 2013;35(3):237-42.

28. Bohlken J, Schömig F, Lemke MR, Pumberger M, Riedel-Heller SG. COVID-19-Pandemie: Belastungen des medizinischen Personals [COVID-19 Pandemic: Stress Experience of Healthcare Workers - A Short Current Review]. Psychiatr Prax. 2020;47(4):190-7.

29. Wicclair R. The pedagogical value of House, M.D. Can a fictional unethical physician be used to teach ethics? AJOB. 2008;8(12): 16-7.

30. Baños JE, Bosch F. Using feature films as a teaching tool in medical schools. Educ Med. 2015;16(4):206-11 


\section{FICHAS TÉCNICAS}

Título: Urgencias (Serie de televisión, 15 temporadas).

Título original: $E R$ (TV Serie).

País: Estados Unidos.

Año: 1994-2009.

Dirección: Michael Crichton (Creador), Christopher Chulack, Jonathan Kaplan, Richard Thorpe, Stephen Cragg, Lesli Linka Glatter, Félix Enríquez Alcalá, Laura Innes, Mimi Leder, Christopher Misiano, John Wells, Paul McCrane, Charles Haid, Andrew Bernstein, Rod Holcomb, Nelson McCormick, David Nutter, Anthony Edwards, Julie Hébert, Tawnia McKiernan, James Hayman, Thomas Schlamme, Paris Barclay, Babu Subramaniam 'T.R.', Jack Orman, Ernest R. Dickerson.

Guion: Michael Crichton, David Zabel, Joe Sachs, John Wells, R. Scott Gemmill, Lydia Woodward, Jack Orman, Lisa Zwerling, Dee Johnson, Neal Baer, Paul Manning, Carol Flint, Janine Sherman, Karen Maser, Virgil Williams, Lance Gentile, Samantha Howard Corbin, Mark Morocco, Sonya Steele, Meredith Stiehm, Linda Gase, Shannon Goss, Walon Green, Robert Nathan.

Música: Martin Davich (Tema: James Newton Howard).

Fotografía: Arthur Albert, Anthony R. Palmieri, Richard Thorpe, Thomas Del Ruth, Héctor R. Figueroa, Jamie Maxtone-Graham, Philip Holahan, Michael Alan Brierley.

Intérpretes: Noah Wyle, Maura Tierney, Laura Innes, George Clooney, Goran Visnjic, Anthony Edwards, Eriq La Salle, Alex Kingston, Sherry Stringfield, Mekhi Phifer, Julianna Margulies, Parminder Nagra, Linda Cardellini, Laura Cerón, Yvette Freeman, Emily Wagner, Lynn A. Henderson, Abraham Benrubi, Deezer D, Paul McCrane, Gloria Reuben, John Stamos, Maria Bello, Angela Bassett, Troy Evans, Lily Mariye, Scott Grimes, Wen Ming-Na, Ellen Crawford, Shane West, William H. Macy, Elizabeth Mitchell,
Thandie Newton, John Leguizamo, Sally Field, Stanley Tucci, Wentworth Miller.

Productora: emitida por NBC; Warner Bros. Television / Amblin Television / Constant C Productions / John Wells Productions.

Género: serie de TV, drama, medicina.

Sinopsis: Prestigiosa serie que narra la vida cotidiana, tanto profesional como personal, del equipo del médicos, enfermeras y administrativos del Servicio de Urgencias del Hospital General de Chicago. Galardonada con más de 20 Premios Emmys y producida, entre otros, por Steven Spielberg (Amblin Television) en asociación con la Warner Bros Inspirada en la obra del famoso guionista y novelista Michael Crichton (Parque Jurásico). Un joven cirujano con síndrome de savant, un tipo de autismo, es reclutado en la unidad quirúrgica pediátrica de un prestigioso hospital. La pregunta se plantea: ¿puede una persona que no tiene plenas capacidades de relacionarse con la gente realmente salvar sus vidas? (Filmaffinity).

Color: color.

Duración: 331 episodios de 45 minutos. https://www.imdb.com/title/tt0108757 https://www.filmaffinity.com/ar/film235350 .html

Título: Anatomía de Grey (Serie de televisión). Título original: Grey's Anatomy (TV Serie).

País: Estados Unidos.

Año: 2005-

Dirección: Shonda Rhimes (Creator), Rob Corn, Chandra Wilson, Tony Phelan, Kevin McKidd, Jeannot Szwarc, Debbie Allen, Tom Verica, Mark Jackson, Peter Horton, Edward Ornelas, Jeffrey Melman, Jessica Yu, Stephen Cragg, Daniel Minahan, Bill D'Elia, Julie Anne Robinson, James Frawley, Allison Liddi, Ron Underwood, Nicole Rubio, Adam Davidson, Wendey Stanzler, Denzel Washington.

Guion: Shonda Rhimes, Stacy McKee, Krista Vernoff, William Harper, Joan Rater, Debora Cahn, Peter Nowalk, Tony Phelan, Mark Wilding, Zoanne Clack, Austin Guzman, Allan Heinberg, 
Meg Marinis, Jen Klein, Tia Napolitano, Jeannine Renshaw.

Música: Danny Lux.

Fotografía: Herbert Davis, Tim Suhrstedt, Adam Kane, Walt Fraser.

Intérpretes: Ellen Pompeo, Patrick Dempsey, Katherine Heigl, Sandra Oh, James Pickens Jr., Chandra Wilson, T.R. Knight, Isaiah Washington, Justin Chambers, Jeffrey Dean Morgan, Kate Walsh, Eric Dane, Sara Ramirez, Chyler Leigh, Mark Saul, Steven W. Bailey, Brooke Smith, Lauren Stamile, Jessica Capshaw, Kevin McKidd, Caterina Scorsone, Jessie Williams, Molly Kidder, Sarah Drew, Kim Raver, Loretta Devine, Gaius Charles, Jerrika Hinton, Camilla Luddington, Jason Winston George, Kelly McCreary, Nicole Rubio, Tessa Ferrer, Kate Burton, Amrapali Ambegaokar, Melissa George, Bresha Webb, Justin Bruening, Amanda Fuller, Rachael Taylor, Janina Gavankar, Abigail Spencer, Geena Davis.

Productora: emitida por ABC; Touchstone Television.

Género: serie de TV, drama, romance, medicina.

Sinopsis: "El famoso Hospital Seattle Grace es el escenario en el que se desarrolla la vida de cinco jóvenes que, tras licenciarse en medicina, empiezan allí un duro periodo de pruebas. La serie ha sido definida como una mezcla entre "Urgencias" y "Sexo en Nueva York", por el interés tanto de las intrigas amorosas como de los casos médicos. La frenética actividad del equipo de cirujanos consigue transmitir el stress al que se ven sometidos los personajes". (Filmaffinity).

Color: color.

Duración: episodios de 45 minutos.

https://www.imdb.com/title/tt0413573

https://www.filmaffinity.com/ar/film237246 .html

Título: Doctor House (Serie de televisión, 8 temporadas).

Título original: House MD (TV Serie).

País: Estados Unidos.
Año: 2004-2012.

Dirección: David Shore, Greg Yaitanes, Deran Sarafian, Juan José Campanella, Miguel Sapochnik, David Straiton, Lesli Linka Glatter, Andrew Bernstein, Katie Jacobs, Daniel Sackheim, Sanford Bookstaver, Daniel Attias, David Platt, Matt Shakman, Peter O'Fallon, Fred Gerber, James Hayman, David Semel, Bryan Spicer, Frederick King Keller, Newton Thomas Sigel, Martha Mitchell, Hugh Laurie, Tucker Gates, Tim Southam, Peter Medak, Paris Barclay, Guy Ferland, Nelson McCormick, Tim Hunter, Keith Gordon, Bill Johnson, Gloria Muzio, Randy Zisk, Jace Alexander, Félix Enríquez Alcalá, Laura Innes, John F. Showalter, Elodie Keene, Matthew Penn, Paul McCrane, Nick Gomez, S.J. Clarkson, Kate Woods, Colin Bucksey, Tony To, Julian Higgins, Stefan Schwartz, Peter Weller.

Guion: David Shore, Peter Blake, Lawrence Kaplow, David Foster, Thomas L. Moran, Russel Friend, Garrett Lerner, Liz Friedman, Sara Hess, Doris Egan, Eli Attie, David Hoselton, John C. Kelley, Pam Davis, Leonard Dick, John Mankiewicz, Matt Witten, Matthew V. Lewis, Seth Hoffman, Kath Lingenfelte.

Música: Jason Derlatka, Jon Ehrlich.

Fotografía: Gale Tattersall, Roy H. Wagner, Anthony Gaudioz, Walt Lloyd.

Intérpretes: Hugh Laurie, Lisa Edelstein, Omar Epps, Robert Sean Leonard, Jennifer Morrison, Jesse Spencer, Olivia Wilde, Bobbin Bergstrom, Peter Jacobson, Anne Dudek, David Morse, Kal Penn, Sela Ward, Edi Gathegi, Chi McBride, Amber Tamblyn, Stephanie Venditto, Andy Comeau, Cynthia Watros, Kayla Colbert, Meta Golding, Jennifer Crystal Foley, Michael Weston, Alexis Thorpe, Wentworth Miller.

Productora: NBC Universal Television / Heel / Toe Films / Shore Z Productions / Bad Hat Harry Productions / Moratim Produktions. Distribuida por Fox Network.

Género: serie de TV, drama, intriga, medicina.

Sinopsis: Gregory House, el mejor médico del hospital, es un hombre antipático que está 
especializado en el diagnóstico de enfermedades. Su carácter extravagante, su rebeldía y su honradez con los pacientes y su equipo lo convierten en una persona única. Trata de evitar la relación con los pacientes, porque lo que le interesa por encima de todo es la investigación de las enfermedades. Es además adicto a los calmantes y a las series de hospitales. (Filmaffinity).

Color: color.

Duración: 176 episodios de 44 minutos. https://www.imdb.com/title/tt0412142 https://www.filmaffinity.com/ar/film709243 .html

Título: El buen doctor (Serie de televisión). Título original: The good doctor (TV Serie). País: Estados Unidos.

Año: 2017-

Dirección: David Shore (Creador), Seth Gordon, Mike Listo, Larry Teng, Cherie Nowlan, Steven DePaul, David Straiton, Allison Liddi, Nestor Carbonell, John Dahl, Regina King, Michael Patrick Jann, Bill D'Elia, Bronwen Hughes.

Guion: David Shore, Karen Struck, Johanna Lee, Lloyd Gilyard Jr., William Rotko, David Renaud, Jae-Beom Park, David Hoselton, Simran Baidwan, Thomas L. Moran.

Música: Dan Romer.

Fotografía: Eric Steelberg, John S. Bartley.

Intérpretes: Freddie Highmore, Nicholas Gonzalez, Beau Garrett, Antonia Thomas, Richard Schiff, Graham Verchere, Dylan Kingwell, Hill Harper, Irene Keng, Chuku Modu, Rose Ranger, Teryl Rothery, Paige Spara, Tamlyn Tomita, Fiona Gubelmann, Christina Chang, Will Yun Lee, Chris D'Elia, Jasika Nicole, Marsha Thomason, Adil Zaidi, Eric Winter.

Productora: emitida por ABC; 3AD / EnterMedia Contents / Shore Z Productions.

Género: serie de TV, drama, medicina, enfermedad.

Sinopsis: "Un joven cirujano con síndrome de savant, un tipo de autismo, es reclutado en la unidad quirúrgica pediátrica de un prestigioso hospital. La pregunta se plantea: ¿puede una persona que no tiene plenas capacidades de relacionarse con la gente realmente salvar sus vidas?" (Filmaffinity).

Premios: 2017: Globos de Oro: Nominada a mejor actor drama (Highmore). 2018: Critics Choice Awards: Nominada a mejor actor (Highmore) y actor sec (Schiff).

Color: color.

Duración: episodios de 41 minutos. https://www.imdb.com/title/tt6470478/ https://www.filmaffinity.com/ar/film445968 .html

Título: The Resident (Serie de televisión). Título original: The Resident (TV Serie).

País: Estados Unidos.

Año: 2017-

Dirección: Phillip Noyce.

Guion: Amy Holden Jones, Hayley Schore, Roshan Sethi.

Intérpretes: Matt Czuchry, Emily Vancamp, Bruce Greenwood, Elizabeth Ludlow, Manish Dayal, Valerie Cruz, Tasie Lawrence, Shaunette Renée Wilson, Mallory Moye, Robin Dyke, Vince Foster, Tequilla Whitfield, Alexa Mansour, Michael Patrick Lane, Jessica Miesel, Megan Chelf Fisher.

Productora: 20th Century Fox Television / 3 Arts Entertainment / Fuqua Films.

Género: serie de TV, drama, medicina.

Sinopsis: Se centra en un joven doctor que empieza su primer día bajo la supervisión de un brillante residente senior que le mostrará la cruda realidad de la medicina moderna. (Filmaffinity).

Color: color.

Duración: episodios de 60 minutos. https://www.imdb.com/title/tt6483832 https://www.filmaffinity.com/ar/film820843 .html

Título: New Amsterdam (Serie de Televisión). Título original: New Amsterdam (TV Series). 
Año: 2018-

Duración: 43 miutos.

País: Estados Unidos.

Dirección: David Schulner (Creador), Kate Dennis, Michael Slovis, Laura Belsey, Peter Horton, Darnell Martin, Jamie Payne, Andrew McCarthy, Jonas Pate, Thomas Carter, Nick Gomez, Stephen T. Kay, Kim So-yong, Ellen S. Pressman, Kristi Zea.

Guion: David Schulner, Joshua Carlebach, Shaun Cassidy, Cami Delavigne, David Foster, Aaron Ginsburg, Erika Green Swafford, Jidéh Breon Holder, Eric Manheimer, Graham Norris, Y. Shireen Razack, Laura Valdivia.

Música: Craig Wedren.

Fotografía: Stuart Dryburgh, Andrew Voegeli. Intérpretes: Ryan Eggold, Christine Chang, Stacey Raymond, Freema Agyeman, Alanna Blair, Lizzy DeClement, Charmar Jeter, Gregory Jones, Anupam Kher, Tyler Labine, Young Mazino, Michael Medeiros, Janet Montgomery, Gary Perez, Emma Ramos, Jay Santiago, Jocko Sims, Raul Torres, Anna Weng, Zabryna Guevara, Alejandro Hernandez, Margot Bingham, Sendhil Ramamurthy, Dierdre Friel, Ron Rifkin, Michael Basile, Christopher Cassarino, Vandit Bhatt, Judith Ivey, Matthew Bellows, Debra Monk, Cindy Cheung, Anthony Ruiz, Mike Doyle, Johanna Day, Michael Pemberton, Kim Ramirez, Katie Lee Hill, Vanessa Kai, Anna Suzuki, Sheila Tapia, Josh Phillip Weinstein, Joanna Adler, Brooke Bloom, Frankie J. Alvarez, Joey Auzenne, Clifton Davis, Cherise Boothe, Tina Chen, Chuck Cooper, Teddy Cañez, Quincy Dunn-Baker, Matthew Maher, Olga Merediz, Michael Cullen, Kate Nowlin, Wai Ching-Ho, David lacono, Johnathan Nieves, Ethan Phillips, Laila Robins, Arthur French, Hayley Lovitt, Kelly
McAndrew, Brian R. Norris, Dale Soules, Ólafur Darri Ólafsson, Ari Barkan, James Saito, Linda Thorson, George Wyner, José Zúñiga, Louis Carbonneau, Therese Plaehn, Lusia Strus, Eric Sheffer Stevens, Shawn Andrew, Joseph Castillo-Midyett, Zack Robidas, Leslie Uggams, Babak Tafti, Tye Alexander, Jamar Greene, Alex Morf, Shirley Rumierk, Jeff Kim, Greg Crowe, Roscoe Orman, Onika Day, Marcus Ho, Michael Puzzo, Joseph Siravo, Tod Engle, John Orantes, Sean Nelson, Tony White, Michael O'Leary, Virginia Vale, Ruibo Qian, Alice Kremelberg, Erica Hernández, Jabari Gray, Aaron Roman Weiner, Melvin Lima, P.J. Sosko, Tanya Thompson, Yan Xi, Nana Mensah.

Productora: Distribuida por National Broadcasting Company (NBC). Universal Pictures Television, Pico Creek Productions, Mount Moriah.

Género: serie de TV, drama, medicina.

Sinopsis: Serie de TV (2018-Actualidad). 2 Temporadas. 40 Episodios. El New Amsterdam se encuentra en una mala situación tanto económica como de reputación. Esto cambiará con la llegada del Dr. Max Goodwin, el nuevo director médico que se propone romper con la burocracia y brindar una atención excepcional. Él no acepta un "no" por respuesta y demostrará que no se detendrá ante nada para dar una nueva vida al hospital, el único en el mundo capaz de tratar a pacientes con ébola y aceptar bajo el mismo techo tanto a presidiarios como al Presidente de Estados Unidos.

Color: color.

Duración: episodios de 60 minutos.

https://www.imdb.com/title/tt7817340/ ?ref_=nv_sr_srsg_0

https://www.filmaffinity.com/es/film294612 .html 


\begin{tabular}{|c|c|}
\hline & $\begin{array}{l}\text { Irene Cambra Badii. Licenciada y Doctora en Psicología. Durante más de } \\
\text { diez años, fue investigadora y profesora en la Universidad de Buenos Aires } \\
\text { (Argentina). Completó su formación postdoctoral en la Universitat Pompeu } \\
\text { Fabra (Barcelona) donde es miembro del Grupo de Investigación en } \\
\text { Educación en Ciencias de la Salud (GRECS) en el Departamento de Ciencias } \\
\text { Experimentales y de la Salud. Desde } 2019 \text { es investigadora en la cátedra de } \\
\text { Bioética de la Universitat de Vic - Universitat Central de Catalunya. }\end{array}$ \\
\hline & $\begin{array}{l}\text { Josep-Eladi Baños. Doctor en Medicina. Ha sido profesor de Farmacología } \\
\text { en la Facultad de Ciencias de la Salud y de la Vida de la Universitat Pompeu } \\
\text { Fabra (2002-2018). Vicerrector de Docencia y Ordenación Académica en } \\
\text { dicha Universidad (2005-2013). Ha dirigido el Grupo de Investigación Edu- } \\
\text { cativa en Ciencias de la Salud de la Universitat Pompeu Fabra (2016-2019). } \\
\text { Ha recibido diversas distinciones a la calidad de la innovación docente de } \\
\text { la Generalitat de Catalunya. Desde } 2019 \text { es Rector de la Universitat de Vic } \\
\text {-Universitat Central de Catalunya. }\end{array}$ \\
\hline
\end{tabular}

